\title{
Comparison of a Standard Dose with a Low Dose of Levobupivacaine in Spinal Anesthesia for Caesarean Section
}

\author{
Ana Sofía Del Castillo Sardi, Alejandro Olivadía, Eva San Martín \\ Children Hospital, Panama City, Panama \\ Email: anasofia113@gmail.com
}

Received 9 October 2014; revised 18 November 2014; accepted 20 December 2014

Copyright (C) 2014 by authors and Scientific Research Publishing Inc.

This work is licensed under the Creative Commons Attribution International License (CC BY).

http://creativecommons.org/licenses/by/4.0/

(c) (i) Open Access

\begin{abstract}
Obstetric anesthesia carries great responsibilities because there are two patients, the mother and the fetus. The purpose of the present study is to compare two doses of Levobupivacaine for spinal anesthesia at elective cesarean section, to determine the best dose that can give mother and fetal hemodynamic stability and a fast anesthesia recovery after the surgery. Method: We conducted a prospective randomized comparative study in 56 patients undergoing cesarean section with spinal dose of Levobupivacaine $6 \mathrm{mg}$ (22 patients) and $10 \mathrm{mg}$ (34 patients), both groups combined with $25 \mu \mathrm{g}$ of fentanyl. The two doses of local anesthetic were compared with regard to sensory and motor blockade, the need for supplementation epidural, the severity of hypotension and other complications. Result: The $6 \mathbf{~ m g}$ of levobupivacaine group presents no difference in the incidence of hypotension, bradycardia, nauseas or vomiting compared with the $10 \mathrm{mg}$ of levobupivacaine group, but presents higher incidence of supplementary analgesia and lower mother satisfaction. Conclusions: The combination of $6 \mathrm{mg}$ of levobupivacaine with $25 \mu \mathrm{g}$ of fentanyl on spinal anesthesia can be an option for short time cesarean section, buy doesn't present a superior profile in side effects over the $10 \mathrm{mg}$ of levobupivacaine with $25 \mu \mathrm{g}$ of fentanyl combination with worst maternal satisfaction.
\end{abstract}

Keywords

Levobupivacaine, Spinal Anesthesia, Cesarean Section

\section{Introduction}

The rate of caesarean section performed in the occidental countries has been increased through the last years. In 
the United States, the births by caesarean sections have been increased from 4.5\% in 1965 to 32.3\% in 2008 [1]. Neuroaxial anesthesia (epidural, spinal or combined epidural-spinal anesthesia) is the preferred technique in the $90 \%$ - 95\% of the caesarean sections [2]-[4].

Obstetric anesthesia entails great responsibilities, because it is being used to treat two patients: the mother and the fetus. Although neuroaxial anesthesia is safe, and spinal anesthesia brings excellent confidence to the anesthesiologist and the surgeon with a great maternal satisfaction, it is not exempt of complications. Some of these complications are hypotension with and incidence reported of $20 \%$ to $100 \%$ [5]-[7], nauseas and vomiting [5], uterus-placental perfusion decrease with fetal acidosis [8] [9] and an incomplete anesthetic blockage that can occur in $25 \%$ of the cases [10].

Exist concrete evidence in literature that support the premise that a reduction in spinal local anesthetic can produce a satisfactory blockage to the surgeon, anesthesiology and the patient with less maternal and fetal hemodynamic side effects; although a standardized dose of local anesthetic that provides a good anesthetic blockage with the lower incidence of side effects is not given [11].

The following article evaluated two different doses of levobupivacaine combined with fentanyl in spinal anesthesia for caesarean section, the standard dose used in our hospital $(10 \mathrm{mg})$ with a lower dose $(6 \mathrm{mg})$; comparing the quality of the blockage and the side effects in each group.

\section{Method}

After institutional ethical approval and informed consent of each patient was obtained, 56 ASA II patients scheduled for elective cesarean section were enrolled in this prospective, randomized simple blind study.

The universe of this study was all the patients programmed to elective cesarean section in the maternity of the Santo Tomas Hospital during the period of the study: March 1 to May 31 of 2013. For the sample calculation the GRANMO version 7.11 program was used, developed by the URLEC consortium. It was use and $\alpha$ risk of 0.05 and a $\beta$ risk if 0.20 with a proportion of 5:1 between the groups, resulting in a sample of 23 patients for each group.

Exclusion criteria were:

- ASA III or more patients

- Patients with emergency cesarean section performed

- Patients under 17 years old

- Patients with less than 37 weeks pregnancy

- Patients in previous labor

- Hemodynamic instable patients

- Patients with hypertensive disruption associated or no with pregnancy

- Patients with known hypersensibility to local anesthetics (amide type)

- Patients with contraindications to spinal blockage

All patients were measured and weight, then 500 cc of lactate ringer was administrated iv during 15 minutes before enter to the operating room. In a box with equal sign (Solution A or Solution B) sealed envelope the anesthesiology of the case choose one envelope. Then the prepared selected solution for the spinal administration was given to the anesthesiologist:

In the operating room after standard monitoring (electrocardiogram, non-invasive blood pressure and oximetry), the patient was located in sitting position. Using aseptic technique L3-L4 epidural space was searched with a Touhy needle $(18 \mathrm{G} \times 3.5$ inches). After that an spinal Sprotte $(25 \mathrm{G}$ o $27 \mathrm{G}$ de $120 \mathrm{~mm}$ ) needle was used through the Touhy needle until the spinal membrane was perforated with cerebrospinal fluid exit. In this point, solution A or Solution B was administrated in the spinal space, then the spinal needle was retired and an epidural catheter (20G Portex of 3 holes) was situated.

After 1 minute of spinal injection, the patient was located in supine position, and non-invasive blood pressure was measured every 2.5 minutes for the first 15 minutes and then every 5 minutes after the caesarean section finished. Hypotension was defined as a 30\% or more blood pressure decrease or a systolic pressure under 100 mmHg. Hypotension was treated with intravenous fluid administration and vasopressors (ephedrine or phenylephrine), according to the anesthesiologist of the case criteria. Bradycardia was defined as a cardiac frequency under 60 beats per minute and was treated with $0.5 \mathrm{mg}$ iv of atropine. A decrease under $93 \%$ in oxygen saturation was treated with supplementary oxygen by nasal cannula. Al the complications was registered for each patient. 


\section{A. S. D. C. Sardi et al.}

The sensitive blockage was evaluated using the pinprick technique (with a 25G needle) and the motor blockage was evaluated using the Bromage scale after 5 and 10 minutes after the spinal solution was administrated and before the surgery began (15 minutes before the combined anesthesia was performed). If the analgesia level was not adequate or if the patient express pain in any stage of the cesarean section, $1.5 \mathrm{cc}$ of levobupivacaine $0.5 \%$ trough the epidural catheter for each dermatome under T4; if that was not enough general anesthesia was performed.

In the post-anesthetic unit level of mother satisfaction and pain using the analogous visual scale was evaluated and was registered.

The result of the incidence of each complication and an average of the analogous visual scale was registered. The comparisons between two qualitative variables were performed with the Pearson's chi-square test. A p value $<0.05$ was considered statically significant. For those cases were the $\mathrm{p}$ value was $<0.05$ the number need to threat (NNT) was calculated.

\section{Results}

A total of 22 patients received the solution A and 34 patients received the solution B (Table 1). Most of the patients of the study were under 30 years old (Table 2) and have a body mass index under 30 (Table 3).

In the group of $10 \mathrm{mg}$ of levobupivacaine, the sensitive blockage T4 was reached quicker (Table 4) and present more motor blockage (Table 5) than the group of $6 \mathrm{mg}$ of levobupivacaine.

Table 1. Distribution by spinal solution administrated.

\begin{tabular}{cc}
\hline Solution A (levobupivacaine $6 \mathrm{mg})$ & Solution B (levobupivacaine $10 \mathrm{mg})$ \\
\hline $22(39.3 \%)$ & $34(60.7 \%)$ \\
\hline
\end{tabular}

Table 2. Distribution by age.

\begin{tabular}{cc}
\hline Age (years old) & Total of patients \\
\hline$<20$ & $6(10.7 \%)$ \\
$20-25$ & $18(32.1 \%)$ \\
$26-30$ & $19(33.9 \%)$ \\
$31-35$ & $11(19.6 \%)$ \\
$36-40$ & $2(3.6 \%)$ \\
\hline
\end{tabular}

Table 3. Distribution by BMI.

\begin{tabular}{cc}
\hline Body mass index & Total of patients \\
\hline $18.5-24.9$ & $3(5.4 \%)$ \\
$25-29.9$ & $35(62.5 \%)$ \\
$30-34.9$ & $15(26.8 \%)$ \\
$35-39.9$ & $3(5.4 \%)$ \\
$\geq 40$ & $0(0 \%)$ \\
\hline
\end{tabular}

Table 4. Incidence of T4 sensitive blockage reached.

\begin{tabular}{ccccc}
\hline & \multicolumn{2}{c}{ Solution A (levobupivacaine 6 mg) } & \multicolumn{2}{c}{ Solution B (levobupivacaine 10 mg) } \\
\hline & Interval (minutes) & Average (minutes) & Interval (minutes) & Average (minutes) \\
\hline Surgical time & $20-63$ & 43.5 & $22-78$ & 45.3 \\
Minimal start of the sensitive blockage & $1-5$ & 2.9 & $1-5$ & 2.9 \\
Maximal star of the sensitive blockage & $4-15$ & 7.3 & $2-10$ & 6.8 \\
\hline
\end{tabular}


The mother satisfaction was greater in the group B (levobupivacaine $10 \mathrm{mg}$ ) (Table 6), and this group also present lower scales of pain using the visual analogous scale (Table 7).

The most common complication for both group hypotension. When the Pearson's chi-square test was applied to compare the qualitative values between the two solutions we only found that the group with the solution B (levobupivacaine $10 \mathrm{mg}$ ) needs less additional doses of local anesthetic through the epidural catheter, with a Number Need to Treat (NNT) of 3 (Table 8).

\section{Discussion}

Anesthesia neuraxial represents increased security for cesarean section to both for the mother and for the product. That's why anesthesia neuraxial is preferred for elective cesarean anesthetic technique and it is also commonly

Table 5. Distribution by motor blockage reached.

\begin{tabular}{|c|c|c|c|c|}
\hline Bromage scale & 0 & 1 & 2 & 3 \\
\hline \multicolumn{5}{|c|}{ At 5 minutes after spinal anesthesia } \\
\hline Solution A (levobupivacine 6 mg) & $3(13.6 \%)$ & $8(36.4 \%)$ & $10(45.5 \%)$ & $1(4.5 \%)$ \\
\hline Solution B (levobupivacaine 10 mg) & $4(11.8 \%)$ & $6(17.6 \%)$ & 18 (52.9\%) & $6(17.6 \%)$ \\
\hline \multicolumn{5}{|c|}{ At 10 minutes after spinal anesthesia } \\
\hline Solution A (levobupivacine 6 mg) & $3(13.6 \%)$ & $6(27.3 \%)$ & $10(45.5 \%)$ & $3(13.6 \%)$ \\
\hline Solution B (levobupivacaine 10 mg) & $4(11.8 \%)$ & $2(5.9 \%)$ & $8(23.5 \%)$ & $20(58.8 \%)$ \\
\hline
\end{tabular}

Table 6. Distribution by mother satisfaction.

\begin{tabular}{ccc}
\hline Mother satisfaction & Solution A (levobupivacaine 6 mg) & Solution B (levobupivacaine 10 mg) \\
Good & $13(59.1 \%)$ & $10(29.4 \%)$ \\
Regular & $7(31.8 \%)$ & $0.6 \%)$ \\
Bad & $2(9.1 \%)$ & $0 \%)$ \\
\hline
\end{tabular}

Table 7. Distribution by visual analogous scale.

\begin{tabular}{ccc}
\hline Visual analogous scale & Solution A (levobupivacaine $6 \mathrm{mg})$ & Solution B (levobupivacaine $10 \mathrm{mg})$ \\
\hline $0-1$ & $15(68.2 \%)$ & $32(94.1 \%)$ \\
$2-4$ & $4(18.2 \%)$ & $2(5.9 \%)$ \\
$5-6$ & $13(13.6 \%)$ & $0(0 \%)$ \\
\hline
\end{tabular}

Table 8. Complications observed in the groups.

\begin{tabular}{|c|c|c|c|c|c|}
\hline & $\begin{array}{c}\text { Solution A } \\
\text { (levobupivacaine } 6 \mathrm{mg} \text { ) }\end{array}$ & $\begin{array}{c}\text { Solution B } \\
\text { (levobupivacaine } 10 \mathrm{mg} \text { ) }\end{array}$ & $\mathrm{X}^{2}$ & $\mathrm{p}$ & NNT \\
\hline Hypotension & $14(63.6 \%)$ & 27 (79.4\%) & 1.69 & $>0.1$ & No apply \\
\hline Bradycardia & $8(36.4 \%)$ & $10(29.4 \%)$ & 0.29 & $>0.1$ & No apply \\
\hline Tachycardia & $8(36.4 \%)$ & $14(41.2 \%)$ & 0.13 & $>0.1$ & No apply \\
\hline Nauseas and vomiting & $6(27.3 \%)$ & $14(41.2 \%)$ & 1.12 & $>0.1$ & No apply \\
\hline Upper blockage & $1(4.5 \%)$ & $3(8.8 \%)$ & 0.37 & $>0.1$ & No apply \\
\hline Need of vasopressors & $13(59.1 \%)$ & 27 (79.4\%) & 2.70 & 0.1 & No apply \\
\hline $\begin{array}{l}\text { Need of additional doses through } \\
\text { the epidural catheter }\end{array}$ & 7 (31.8\%) & $3(8.8 \%)$ & $4.81 \varnothing$ & 0.05 & 3 \\
\hline
\end{tabular}

Statistically significant. 
used for cesarean sections unscheduled or emergency.

Spinal anesthesia is more reliable than epidural anesthesia, because brings a more intense motor and sensitive blockage. Although, the superior level of blockage can be variable and the fetus can be exposed to complications secondary to maternal hypotension. Because spinal anesthesia is generally given in a unique dose, there is no possibility to strengthen incomplete blockage and continues postoperative analgesia [12].

The resurgence of the spinal anesthesia like popular technique has been possible because the development of thinner needles and became the preferable method for elective cesarean and for the majority of emergency cesarean [13].

Anesthesia textbook recommend the doses of levobupivacaine up to $15 \mathrm{mg}$ [14], but the use of this dose have been associated with a great incidence of maternal hypotension, becoming important maternal and neonatal morbidity. A great number of studies treat to estimate the optimal dose of levobupivacaine, but the finding are not uniform, with doses range between 5 to $20 \mathrm{mg}$ [15]. The use of lower doses may help to reduce de adverse maternal effects [hypotension, nauseas, vomiting), reducing egress time in the post anesthetic unit and increasing maternal satisfaction [16]. Although, these strategy can produce an inadequate anesthetic blockage and required supplementary analgesia or a general anesthesia; and known situation of risk factor of maternal mortality and morbidity [17].

In the literature are concrete evidence that reduce spinal doses of local anesthetic in cesarean section can produce an effective anesthetic blockage with less hemodynamic adverse effects for the mother and the fetus. Parpaglioni and cols compared the use of levobupivacaine for cesarean section in a range of dosis of 10 to $12 \mathrm{mg}$ obtaining a good response [18], but in this study they don't give information about the incident of side effects.

Vercauteren et al. [19] [20] and Choi et al. [21] used small doses of bupivacaine combined with opioids, obtaining excellent anesthetic results. De Santiago et al. [22] use levobupivacaine doses between $3 \mathrm{mg}$ to $5 \mathrm{mg}$; all of them supplemental with $10 \mu \mathrm{g}$ of fentanyl dilute until $3 \mathrm{~mL}$ of sterile water. They found that doses of $5 \mathrm{mg}$ and $4 \mathrm{mg}$ were enough to produce and adequate anesthesia, but doses of $3 \mathrm{mg}$ were insufficient. In our study the dose of $6 \mathrm{mg}$ of levobupivacaine was enough in the $68.2 \%$ of the cases, related to the duration of the cesarean section. There are limited studies that bring information the optimal doses to achieve a satisfactory anesthesia with lower incidence of side effects.

A meta-analysis compare doses over and lower 8mg of bupivacaine, and found less side effects but higher need of supplementary analgesia in the lower 8mg group [23]. In our study the group with $6 \mathrm{mg}$ of levobupivacaine doesn't present a better profile in side effects that the $10 \mathrm{mg}$ group, and require more supplementary analgesia (NNT of 3, good result for clinical experience) and present lower maternal satisfaction.

\section{Conclusion}

The combination of $6 \mathrm{mg}$ of levobupivacaine with $25 \mu \mathrm{g}$ of fentanyl on spinal anesthesia can be an option for short time cesarean section, but doesn't present a superior profile in side effects over the $10 \mathrm{mg}$ of levobupivacaine with $25 \mu$ g of fentanyl combination with worst maternal satisfaction.

\section{References}

[1] Guise, J.M., Denman, M.A., Emeis, C., et al. (2010) Vaginal Birth after Cesarean: New Insights on Maternal and Neonatal Outcomes. Obstetrics \& Gynecology, 115, 1267-1278. http://dx.doi.org/10.1097/AOG.0b013e3181df925f

[2] Morgan, B.M., Aulakh, J.M., Barker, J.P., Goroszeniuk, T. and Trojanowski, A. (1983) Anaesthesia for Caesarean Section-A Medical Audit of Junior Anaesthetic Staff Practice. British Journal of Anaesthesia, 55, 885-889. http://dx.doi.org/10.1093/bja/55.9.885

[3] Bucklin, B., Hawkins, J., Anderson, J. and Ullrich, F. (2005) Obstetric Anesthesia Workforce Survey. Anesthesiology, 103, 645-653. http://dx.doi.org/10.1097/00000542-200509000-00030

[4] Rahman, K. and Jenkins, J.G. (2005) Failed Tracheal Intubation in Obstetrics: No More Frequent but Still Managed Badly. Anaesthesia, 60, 168-171. http://dx.doi.org/10.1111/j.1365-2044.2004.04069.x

[5] NganKee, W.D., Khaw, K.S., Lee, B.B., et al. (2000) A Dose-Response Study of Prophylactic Intravenous Ephedrine for the Prevention of Hypotension during Spinal Anesthesia for Cesarean Delivery. Anesthesia \& Analgesia, 90, 13901395. http://dx.doi.org/10.1097/00000539-200006000-00024

[6] Rout, C.C., Rocke, D.A., Levin, J., et al. (1993) A Reevaluation of the Role of Crystalloid Preload in the Prevention of Hypotension Associated with Spinal Anesthesia for Elective Cesarean Section. Anesthesiology, 79, 262-269.

http://dx.doi.org/10.1097/00000542-199308000-00011 
[7] Tercanli, S., Schneider, M., Visca, E., et al. (2002) Influence of Volume Preloading on Uteroplacental and Fetal Circulation during Spinal Anaesthesia for Caesarean Section in Uncomplicated Singleton Pregnancies. Fetal Diagnosis and Therapy, 17, 142-146. http://dx.doi.org/10.1159/000048027

[8] Roberts, S.W., Leveno, K.J., Sidawi, J.E., et al. (1995) Fetal Acidemia Associated with Regional Anesthesia for Elective Cesarean Delivery. Obstetrics \& Gynecology, 85, 79-83. http://dx.doi.org/10.1016/0029-7844(94)P4401-9

[9] Reynolds, F. and Seed, P.T. (2005) Anaesthesia for Caesarean Section and Neonatal Acid-Base Status: A Meta-Analysis. Anaesthesia, 60, 636-653. http://dx.doi.org/10.1111/j.1365-2044.2005.04223.x

[10] Larsen, J.V. (1982) Obstetric Analgesia Anaesthesia. Clin Obstet Gynecol., 9, 685-709.

[11] Roofthooft, E. and Van de Velde, M. (2008) Low-Dose Spinal Anaesthesia for Caesarean Section to Prevent SpinalInduced Hypotension. Current Opinion in Anaesthesiology, 21, 259-262. http://dx.doi.org/10.1097/ACO.0b013e3282ff5e41

[12] Datta, S. and Alper, M.H. (1980) Anesthesia for Cesarean Section. Anesthesiology, 53, 142-160. http://dx.doi.org/10.1097/00000542-198008000-00008

[13] Gogarten, W. (2003) Spinal Anaesthesia for Obstetrics. Best Practice \& Research Clinical Anaesthesiology, 17, 377392. http://dx.doi.org/10.1016/S1521-6896(02)00116-7

[14] ABBOTT LABORATORIES. CHIROCAINA, Solución Inyectable. Anestésico local. [sede Web]. México Medicamentos.com.mx. www.medicamentos.com.mx/DocHTM/25843.htm

[15] Cyna, A.M., Andrew, M., Emmett, R.S., et al. (2007) Techniques for Preventing Hypotension during Spinal Anaesthesia for Caesarean Section [Review]. The Cochrane Library, (4).

[16] Practice Guidelines for Obstetric Anesthesia (2007) An Updated Report by the American Society of Anesthesiologists Task Force on Obstetric Anesthesia. Anesthesiology, 106, 843-863.

[17] Gaiser, R. (2006) Postdural Puncture Headache. Current Opinion in Anesthesiology, 19, 249-253.

[18] Parpaglioni, R., et al. (2006) Minimun Local Anaesthetic Dose (MLAD) of Intrathecal Levobupivacaine and Ropivacaine for Caesarean Section. Anaesthesia, 61, 110-115. http://dx.doi.org/10.1111/j.1365-2044.2005.04380.x

[19] Vercauteren, M.P., Coppejans, H.C., Hoffmann, V.L., et al. (1998) Small-Dose Hyperbaric versus Plain Bupivacaine during Spinal Anesthesia for Cesarean Section. Anesthesia and Analgesia, 86, 989-993.

[20] Vercauteren, M.P., Coppejans, H.C., Hoffman, V.H., et al. (2000) Prevention of Hypotension by a Single 5-mg Dose of Ephedrine during Small Dose Spinal Anesthesia in Prehydrated Cesarean Delivery Patients. Anesthesia and Analgesia, 90, 324-327.

[21] Choi, D.H., Ahn, H.J. and Kim, J.A. (2006) Combined Low-Dose Spinal-Epidural Anesthesia versus Single Shot Spinal Anesthesia for Elective Cesarean Delivery. International Journal of Obstetric Anesthesia, 15, 13-17. http://dx.doi.org/10.1016/j.ijoa.2005.05.009

[22] De Santiago, J., Santos-Iglesias, J., Girón, J., Jiménez, A. and Errando, C.L. (2011) Low-Dose, Low-Concentration Levobupivacaine plus Fentanyl Selective Spinal Anesthesia for Knee Arthroscopy: A Dose Finding Study. Anesthesia \& Analgesia, 112, 477-480. http://dx.doi.org/10.1213/ANE.0b013e318202cd03

[23] Anzoea, C. and Wiechorek, P.M. (2011) Efficacy of Low-Dose Bupivacaine in Spinal Anesthesia for Caesareum Delivery: Systemic Review and Meta-Analysis. British Journal of Anaesthesia, 107, 308-318. http://dx.doi.org/10.1093/bja/aer200 
Scientific Research Publishing (SCIRP) is one of the largest Open Access journal publishers. It is currently publishing more than 200 open access, online, peer-reviewed journals covering a wide range of academic disciplines. SCIRP serves the worldwide academic communities and contributes to the progress and application of science with its publication.

Other selected journals from SCIRP are listed as below. Submit your manuscript to us via either submit@scirp.org or Online Submission Portal.
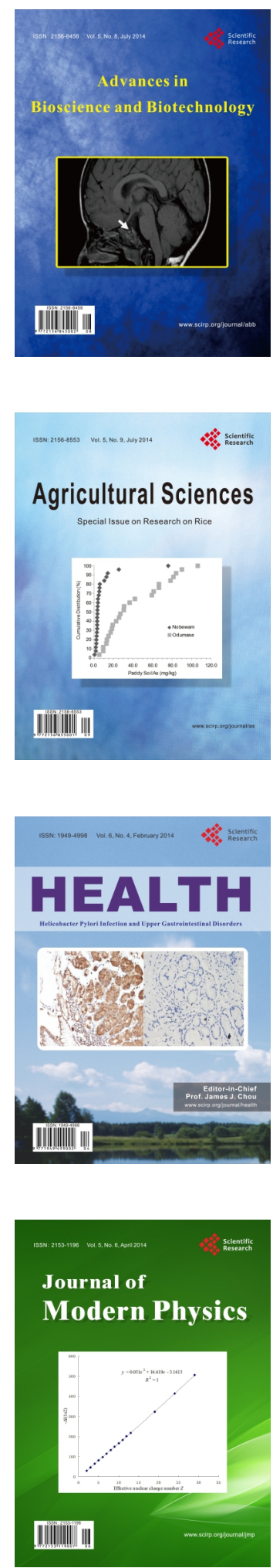
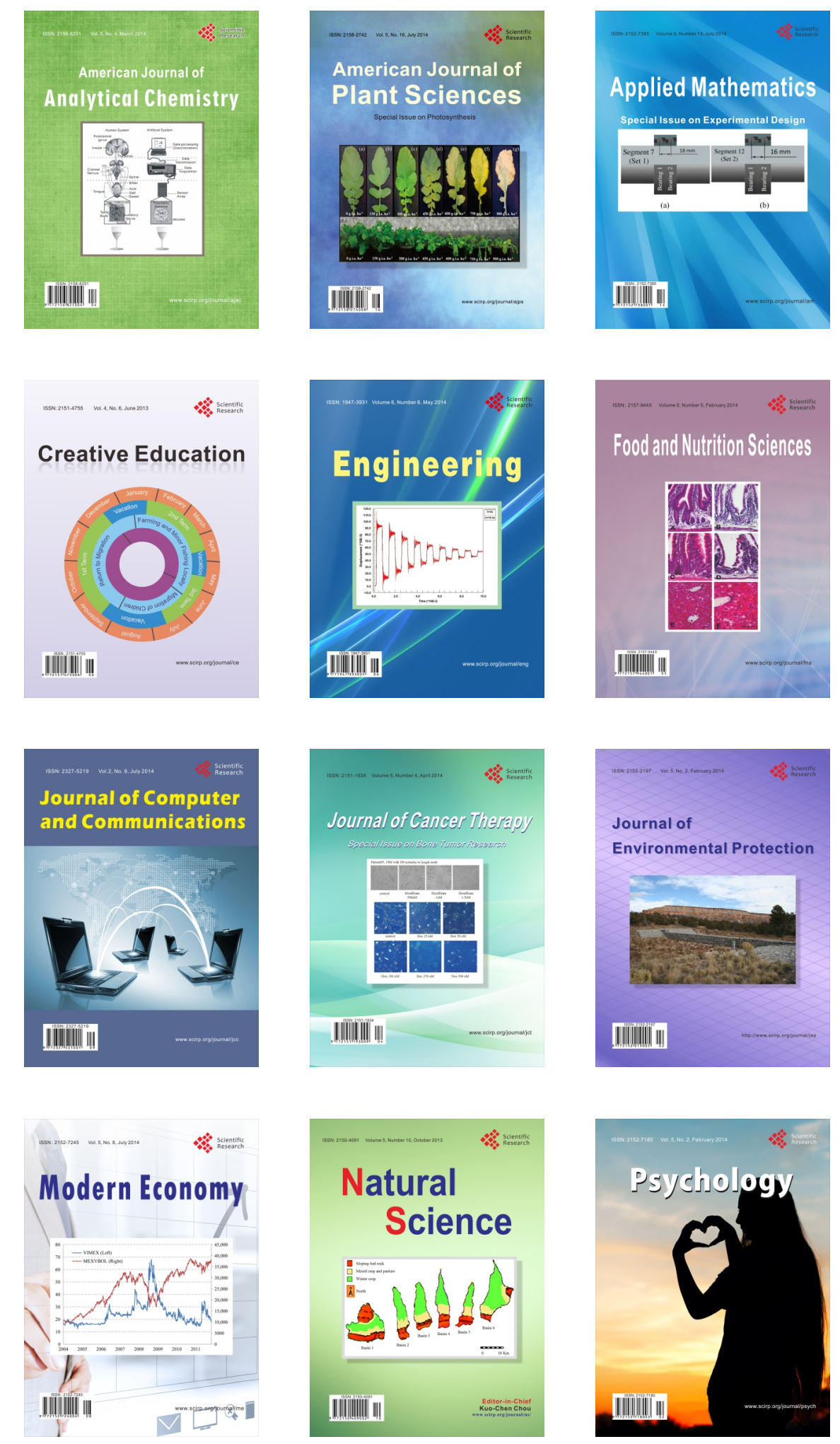